\title{
Environmental safety in the field of construction and operation of hydraulic structures
}

\author{
Trofim Shkrebtii ${ }^{1, *}$, Andrei Cherkasov ${ }^{1}$, Tamara Nebozh $^{1}$, Alexandr Muraviev ${ }^{1}$, and Ruslan \\ Taroev $^{1}$ \\ ${ }^{1}$ Far Eastern Federal University, 10 Ajax Bay, Russkiy Island, 690922, Vladivostok, Russia
}

\begin{abstract}
The article deals with the environmental safety of construction production, as well as the process of operation using examples of hydraulic structures. The purpose of the article is to show the growing importance of taking into account environmental decisions and measures in the design of the construction project and operation manual. The objectives are to identify and systematize implemented examples of environmental solutions. The objects of the study are hydraulic structures: mooring, river and shelf. The tasks are solved by methods of searching for information on the issues under consideration as part of the analytical review, with further discussions and conclusions. It was revealed that in recent years, environmental expertise has become more stringent in assessing and allowing hydraulic facilities to begin construction and installation work and commissioning, due to the accumulated negative experience of accidents, flooding and other harmful environmental influences. As a result of the analytical review, we obtain generalized conclusions on modern trends in orienting new construction in the primary interests of environmental protection.
\end{abstract}

\section{Introduction}

Environmental protection is one of the priority tasks in any project, including construction. Changes in natural order and pollution of the natural environment lead to the disruption of the universal balance of processes on Earth, which also affects human life to a large extent. Various natural disasters and phenomena, as the experience of past and present centuries shows, occur in most cases due to human intervention.

At the same time, the construction of buildings and structures in the territories and waters of the natural habitat of the flora and fauna families has a very significant impact, which forces the latter to migrate and adapt with great difficulty to other lands that are undeveloped by humans. But even this migration scenario can be called positive, due to the fact that often migrating individuals do not adapt to the new conditions, or do not have time to migrate at all, which entails their death. The most striking examples show the construction of a new hydroelectric dam, for which huge areas of land are flooded. These and other examples will be set forth in this article below.

\footnotetext{
* Corresponding author: blazblue@list.ru
} 
The impact of urbanized territories on the environment and the very quality of the environment in the construction area in the existing development is determined primarily by the decisions laid down during the design, then, respectively, by the quality of execution and further - by the operating conditions of the facilities. The degree of environmental validity and thoughtfulness of projects largely determines not only the future state of the environment, but also the amount of future socially necessary labor costs and funds for restoring disturbed natural conditions.

Speaking specifically about hydraulic construction, it should be said that such construction is the largest water consumer. Water is used for the following needs: preparation of concrete mixture, concrete cooling and care; washing of inert aggregates (gravel, sand) for concrete; injection works to fix the soil of the base, with the creation of anti-filtration curtains, cementation of temporary (temperature-shrinkage) joints of concrete dams with columnar cutting; heat and water supply, cooling of engines and process units; washing of machines, mechanisms, equipment for concrete preparation and transportation; soil washing during erection of soil dams by hydromechanics (up to $10 \mathrm{~m} 3$ of water is required for laying $1 \mathrm{~m} 3$ of soil in the dam body); and other needs. While water contaminated in all of the above processes is generally not purified and is contaminated in a clean water body.

The described and many other reasons signal the relevance of the environmental problem only in hydrotechnical construction, not to mention operation, which is especially acute in the structures of the continental shelf engaged in the extraction of hydrocarbons.

\section{Materials and methods}

The materials of the environmental safety analysis on the construction and operation of hydraulic structures are the latest articles of reputable scientific publishers, information in the form of news and reports on environmental solutions in construction and operation projects from reliable sources.

The methods are based on a comprehensive analytical review of the relevant information found, followed by the systematization of the main ideas. After a comprehensive review and the selection of semantic excerpts, general conclusions are drawn about the trend of increasing growth in environmental safety in the area under consideration.

Objects located in the territory of both the Russian Federation and other states are considered. Among all hydraulic structures, the most influential on the environment are: river, mooring (sea) and shelf. In this regard, examples of the listed structures will be considered.

\section{Results}

The first example provides general information on the present situation of accounting for the environmental safety of any, including hydraulic, construction in the Russian Federation. At present, for all construction facilities without exception, mandatory project examination is required for all the sections presented, including the "List of Environmental Protection Measures (EHS)," which involves environmental protection for the initial period of operation. Obtained indicators meeting all environmental protection requirements change for both better and worse during the period of operation.

In connection with the change in the project calculation indicators of environmental protection, it is preferable to carry out environmental monitoring, which will allow the development and organization of an observation system, assessment and forecast of the 
state of the environment. The main principle of monitoring is continuous tracking. According to the territorial coverage, three stages or blocks of modern monitoring are distinguished - local (bioecological, sanitary), regional (geosystem), global (biosphere, background). In Russia, functioning an extensive national surveillance service at all stages of monitoring, summarizing the results of which obtain an objective picture of anthropogenic and natural processes. Observations of individual environmental objects are carried out by various state and departmental services: the Center for Hydrometeorology and Environmental Monitoring (TsGMS), the Center for State Sanitary Surveillance (TsSEN), the Ministry of Natural Resources (MPR), the Land Resources Committee, etc.

Let us highlight in more detail in the following example the negative effects in the construction of hydraulic structures, which have now become more strictly taken into account in subsequent construction projects. Among these influences: harmful chemicals, which can also enter reservoirs following the leaching of concrete of dams and the erosion of formations containing vegetable and Roman substances at the base of the soil during filtration of groundwater; the development of quarries of building materials causes a change in groundwater storms, soil erosion; the construction of hydraulic structures on rivers leads to an isma of their hydrological regime, reformation of the banks, flooding of significant areas, as shown by Figure 1 .

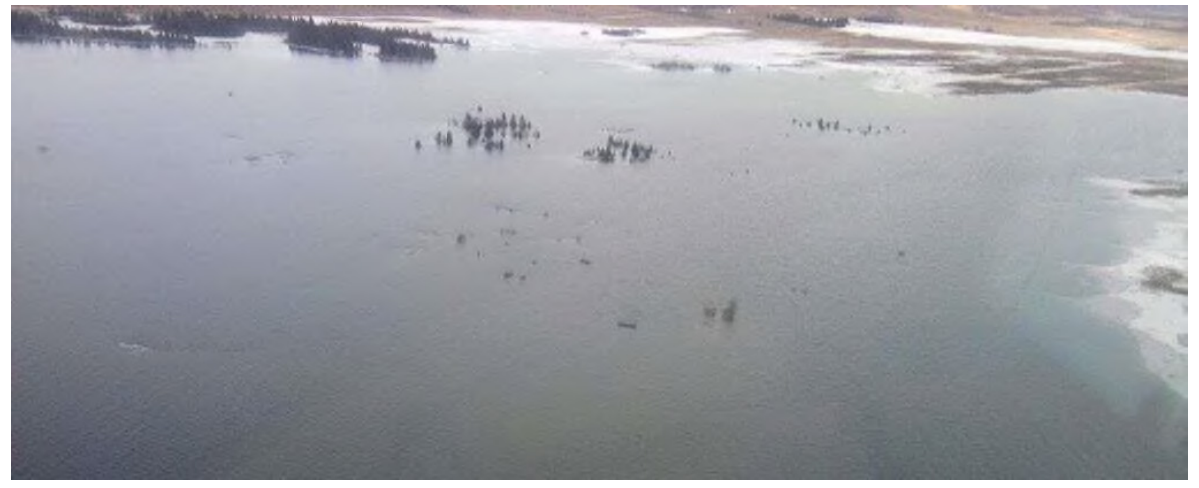

Fig. 1. Flooding of land during the construction of the Boguchanskaya hydroelectric station in Siberia of Russia.

Many types of special works in hydraulic engineering construction (drilling, blasting, anti-filtration, water reduction and soil fixation) have a multilateral negative impact on natural ecological systems, with natural landscapes, disturb the ecological balance and cause significant damage to the state of the environment. Therefore, it was necessary to develop those work methodologies and to apply building materials that made it possible to reduce anthropogenic loads on natural ecosystems as much as possible.

In order to preserve natural soil, and to a greater extent groundwater, a mandatory environmental assessment of the use of injection solutions for anti-filtration and strengthening measures has recently been carried out. So, the project of one of the hydroelectric assemblies was the penetration of tunnels through the fault zones with preliminary strengthening of rocks by cementation and the subsequent injection of chemical solution of tars based on urea-formaldehyde (carbamide) resins together with a hardener oxalic acid. In the laboratory of Hydrospets-Project LLC in the same years, studies were carried out to determine the intenicity of the release of free fluoro-maldehyde from solutions of urea-formaldehyde resins and from cured resin. Defined quantity of the forkmaldegid allocated by gel of carbamide pitch from a surface (zakrepklenny soil), at gel violation (development of the fixed soil) and at his distribution to surfaces (flood). 
The following example relates to the removal of harmful dissolution products by filtration waters. At the end of the last century, the construction of the Katun hydroelectric station on the Katun River (Altai) began. However, the potential for washing mercury from rocks in the area of the future reservoir caused serious concern for the preservation of environmental information about the installation in the region and forced to abandon this project. In this regard, particular attention was paid to the selection of a binder that is most resistant to the aggressive influence of a salt solution $(\mathrm{NaCl})$. To prepare an injection of solutions, cements were used several times of a personal mineralogical composition. As a result of studies, it was established that all solutions prepared on brine have a lower other compression strength than those prepared on water, and with an increase in the end of brine traction, the strength of cement stone sharply decreases.

Next, consider an example related to oil production, namely well construction. One of the fundamental principles of environmental activity both in OAO Gazprom in general and in the Drilling Company in particular, which is being introduced into everyday practice, is "From the face of pollution exposure - to the environment of cleaner production." The growth of production activities, including during the construction of production and production wells, leads to an increase in the influence of humans on nature as its habitat. Well construction has a number of special physical features, determining the level of manmade influence and the volume of pollution of the environment of the natural environment. Of all the stages of development of oil and gas fields - from drilling to the trans-port of produced raw materials - the builder, well construction is the first and most significant invasion of the environment.

The integrated approach to improving the level of environmental safety of production, implemented at the Drilling Company's enterprises, allowed the environmental service to develop and implement the main elements of the environmental management system. They include information and communication structures, planning, distribution of responsibility response, training of personnel, conducting inspections and corrective actions. This made it possible to approach the formulation of the basis of the environmental regulations on the policy, which consists in a health wound and ensuring without danger of working personnel, minimizing the technological impact on the natural environment through the introduction of low and waste-free technologies.

The main requirement of precautionary legislation in the performance of drilling operations in conservation zones is barrage-free drilling, which involves the collection, removal and burial of drilling products outside these zones. It is obvious that these requirements lead to a complication of technological and organizational decisions and an increase in costs for drilling bots.

Naturally, in such situations, the main task of the Drilling Company is to optimize the cost of drilling operations, according to which there is no need to expect any decrease in drilling volumes in zones with a special nature protection status in the coming years, rather, on the contrary, their further growth will be expected here. One of the options for extraction of hydrocarbon resources of offshore structures is drilling of subgorizontal and inclineddirected wells, having the form shown in Figure 2, with large waste from the shore.

Consider an example of environmental measures in the development of the Prirazlomnaya marine ice-resistant stationary platform. An important component of the measures is the preservation of the environment and marine biota in the area of the location of the Prirazlomnaya platform within the border of the mineral area of the Prirazlomnoye oil field in the Pechora Sea. Monitoring has been carried out annually since 2010. During the period of construction and commissioning work on the platform, no significant anthropogenic impact on the environment has been recorded. as of January 1 , 2017, the content of pollutants corresponds to permissible indicators and falls within the ranges of previously observed indicators. Monitoring is carried out within the radius of the 
islands of Dolgiy, Matveev, Big and Small Zelentsy and Vaigach. Ecosystem studies were carried out by Gazprom Neft Shelf LLC and Frecom. The process involved oceanologists of the Polar Research Institute of Marine Fisheries and Oceanography (FSUE PINRO) and employees of the scientific department of the Nenets State Nature Reserve.

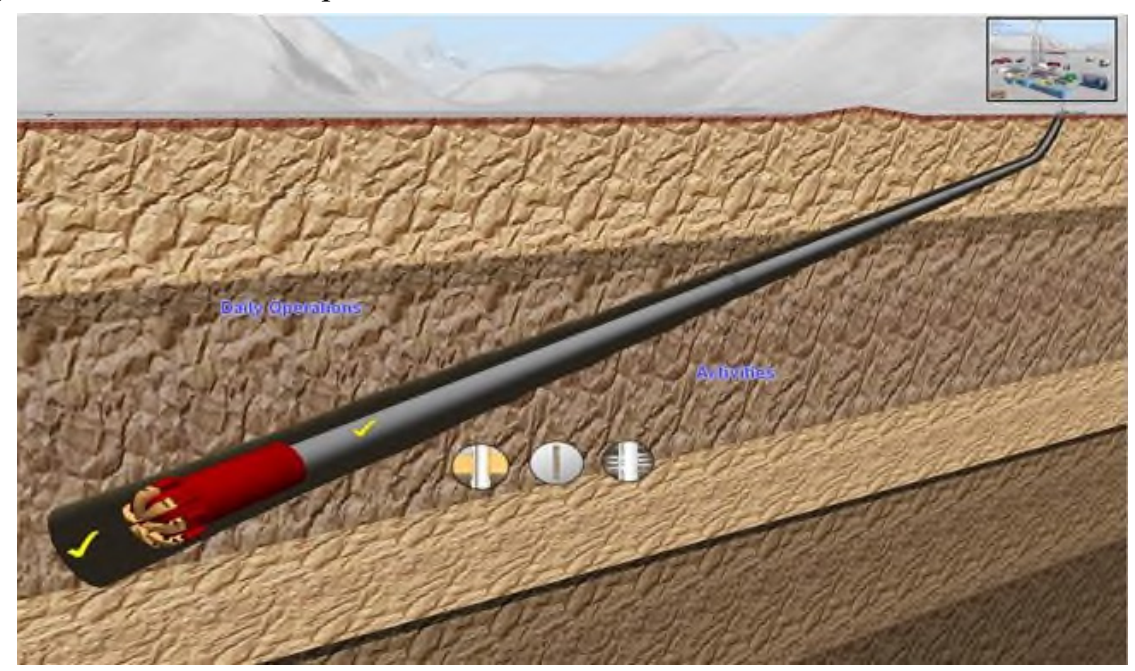

Fig. 2. Conceptual diagram of directional drilling of wells for maximum distance from the shore (barrage-free drilling).

The main environmental measures at the Prirazlomnaya MLSP are: the creation of a system of industrial environmental control and environmental monitoring; elimination of oil leaks due to application of modern well design; Disposal of drilling and production waste (sludge and wastewater) by injection into the absorption well or onshore (packagings, mercury lamps, batteries and others); oil spill prevention and management system (LRN) in accordance with the approved LRN Plan; protection of marine inhabitants - water intake through fish protection devices of the "blinds" type; bioresource recovery through the release of diluted fish; protection of birds by means of a special bioacoustic installation. It is necessary to notice that the listed above events are realized, their list in the period of lack of emergency events is dostatochkny. However, the development project plans a wider list of them.

Examples abroad of Russia.

The author of one article [3] confirms the idea of taking environmental decisions into account at the design stage more thoroughly: "Making decisions at the early stages of designing structures critically affects the total cost and environmental characteristics of buildings and infrastructure. However, the current approach often fails to address the multidimensional aspects of structural design, such as safety, environmental concerns and costs, in an integrated manner. "

In Poland, the question was raised of "controlled variability of thermal and oxygen conditions on the block hydraulic structure of the ramp: the Porenbyanka River, the Polish Carpathians" [4]. An example of a solution in the form of hydraulic structures of the Block ramp (BR) shown in Figure 3 is given.

In the United States, the problem of fracturing in the development of shale gas [5] for reference and further use in the development and management of shale gas in China has been addressed.

In India, man-made activity in the Krishna River changed its course and affected ecosystems in the river, according to the authors of article [6]. A study is described in five 
sections of the Krishna River dam before and after construction. Data on shock flows were collected at downstream stations and showed insufficient habitability of natural marine inhabitants in the studied area.
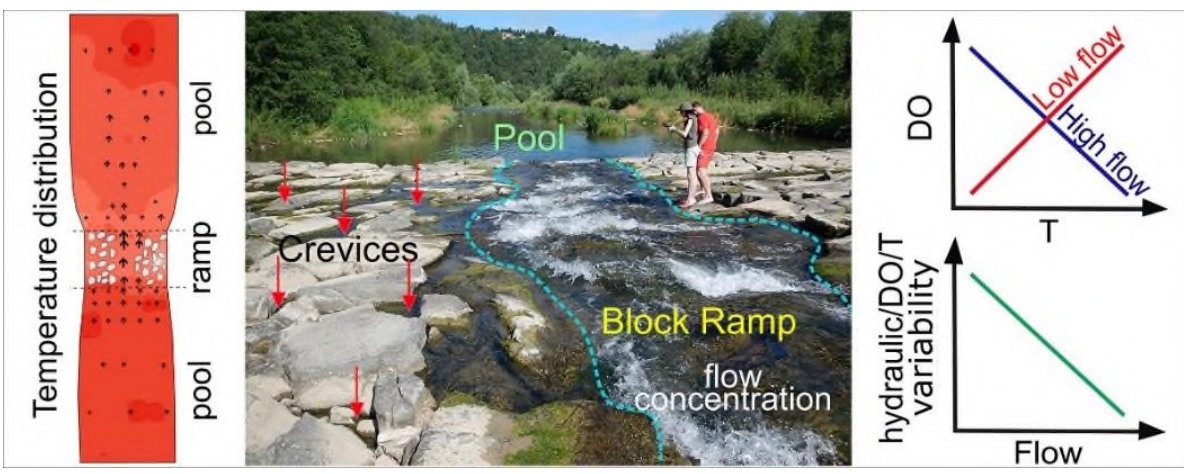

Fig. 3. Conceptual diagram of hydraulic structure of block ramp.

South Korea was developing "a new cementless binder for stabilizing marine soil: strength behavior, hydraulic resistance, microstructural analysis and environmental impact" [7].

United Kingdom considered a change in the fleet of pumps [8] used in hydraulic fracturing in Europe, due to the insufficient ability of these pumps to eliminate ecosystem pollution. Pollution and transport problems are of paramount importance for the fracturing industry in Europe and it is therefore important to consider these factors when evaluating the design of high pressure pumps.

Australian researchers studied factors of influence on hydraulic characteristics of geosynthetic clay lining [9]. As the scientists noted: "The results of this study will help minimize failures of liner systems in barrier applications, such as landfills, mines, tailings dams, significantly reducing the potential risk of groundwater pollution."

The issue of solving the problem of hydraulic fracturing was also solved in Canada, where the emphasis was on British Columbia and Alberta [10].

In the United States, the heterogeneity of hydraulic conductivity and porosity is monitored for environmental performance [11]. The monitoring examines the implications for the probabilistic analysis of risks to the ecosystem.

The environmental and hydraulic impacts of the future geological waste repository at the Meuse site in France [12] are carried out using specially developed numerical and polynomial modelling.

In China, attention is paid to the hydraulic architecture of three types of karagan and its connection with environmental factors in various habitats of the Inner Mongolian Plateau [13]. Also, environmental regulations are already influencing the modernization of industrial structures: An empirical study on the Beijing-Tianjin-Hebei region [14].

Scientists of the Republic of Korea solve the problem of "detecting oil leakage in the ground by controlling impedance using time domain reflectometry and hydraulic control system." [15].

\section{Discussions}

Having considered many examples of environmental solutions, we will highlight the main ideas. 
The first example in Russia, involving mandatory environmental expertise and several specialized state and departmental services, shows the importance of the issue at the state level.

As it turned out, for the possession of information about the current environmental situation, a project "Spatial-dynamic modeling of environmental safety of the regions of the Russian Federation" is being developed, which is likely to be very costly.

To preserve the cleanliness of soil and groundwater during the construction of river waterworks (dams of power plants), measures are used to ecological assessment of infectious solutions, laboratory analysis and development of a composition that does not harm the ecosystem.

In the oil and gas industry, one of the priorities, as we saw, is the introduction of elements of the environmental management system. The purity of oil production itself, that is, the operation of offshore structures, is achieved by drilling systems of subhorizontal and inclined-directed wells. On the example of MLSP "Prirazlomnaya," among the environmental protection measures listed above, measures for the protection of marine inhabitants are also identified.

Outside the Russian Federation, the problem of hydraulic fracturing and environmental decision-making in the United States, China, United Kingdom, Canada is most acutely addressed.

Many countries are currently dealing with groundwater cleanliness issues following the use of modern injectable solutions and other binders, such as in South Korea and Australia.

Integrated environmental monitoring projects are also available using examples from India, the United States, France, China and the Republic of Korea.

\section{Conclusions}

Examples of solutions to environmental problems considered in the framework of the integrated analytical review showed the very significant role of environmental protection issues at the stages of construction and operation projects at the current moment.

The hypothesis of increasing attention to environmental issues in construction was also confirmed on the basis of vivid examples of modeling, monitoring and control of the state of the ecosystem in areas adjacent to hydraulic structures. This summary information will serve as another reason for transforming the design system in the world as such, where the location of the environmental safety section will be more significant and significant.

\section{References}

1. V. Glinskiy, L. Serga, M. Khvan, K. Zaykov, A Spatio-dynamic Modelling of Environmental Safety of the Russian Federation Regions, Procedia Manufacturing 8, (2017)

2. Y. Filippova, L. Matyushina, Main Activities in the Field of Environment Protection and Environmental Safety in Operation of St. Petersburg Metro Facilities, Procedia Engineering 165, (2016)

3. Z. Jisong, L. Haijiang, Z. Yinghua, R. Guoqian, An ontology-based approach supporting holistic structural design with the consideration of safety, environmental impact and cost, Advances in Engineering Software 115, (2018)

4. A. Rajwa-Kuligiewicz, A. Radecki-Pawlik, T. Skalski, K. Plesiński, P. Rowiński, R. Manson, Hydromorphologically-driven variability of thermal and oxygen conditions at 
the block ramp hydraulic structure: The Porębianka River, Polish Carpathians, Science of The Total Environment 713, (2020)

5. D. Zhang, T. Yang, Environmental impacts of hydraulic fracturing in shale gas development in the United States, Petroleum Exploration and Development 42, (2015)

6. A.U. Kumar, K.V. Jayakumar, Modelling of environmental flow requirements using hydraulic and habitation models (Ecological Indicators, 2020)

7. D.T. Manh, G. Kang, N. Vu, Y. Kim, Development of a new cementless binder for marine dredged soil stabilization: Strength behavior, hydraulic resistance capacity, microstructural analysis, and environmental impact, Construction and Building Materials 186, (2018)

8. A. Josifovic, J. Roberts, J. Corney, B. Davies, Z. Shipton, Reducing the environmental impact of hydraulic fracturing through design optimisation of positive displacement pumps, Energy 115, (2016)

9. I. Weerasinghe, C. Gallage, L. Dawes, P. Kendall, Factors affecting the hydraulic performance of a geosynthetic clay liner overlap, Journal of Environmental Management 271, (2020)

10. P. Larkin, R. Gracie, M. Dusseault, D. Krewski, Ensuring health and environmental protection in hydraulic fracturing: A focus on British Columbia and Alberta, Canada, The Extractive Industries and Society 5, (2018)

11. A. Libera, C. Henri, F. Barros, Hydraulic conductivity and porosity heterogeneity controls on environmental performance metrics: Implications in probabilistic risk analysis, Advances in Water Resources 127, (2019)

12. J. Kerrou, J. Deman, L. Tacher, H. Benabderrahmane, P. Perrochet, Numerical and polynomial modelling to assess environmental and hydraulic impacts of the future geological radwaste repository in Meuse site (France), Environmental Modelling \& Software 97, (2017)

13. L. Jing, G. Yubao, Z. Zhirong, G. Zenglu, Hydraulic architecture of three Caragana species and its relationship with environmental factors in different habitats of the Inner Mongolian Plateau, China, Acta Ecologica Sinica 27, (2007)

14. G. Zhang, P. Zhang, Z. Zhang, J. Li, Impact of environmental regulations on industrial structure upgrading: An empirical study on Beijing-Tianjin-Hebei region in China, Journal of Cleaner Production 238, (2019)

15. S. Lee, K. Know, B. Kim, J. Choi, S. Lee, Detection of oil leakage in soil by monitoring impedance using time domain reflectometry and hydraulic control system, Process Safety and Environmental Protection 127, (2019) 